\title{
Copper (sub)oxide formation: a surface sensitive characterization of model catalysts
}

\author{
Thomas Schedel-Niedrig,* Thomas Neisius, Ingolf Böttger, Edith Kitzelmann, Gisela Weinberg, \\ Dirk Demuth and Robert Schlögl
}

Fritz-Haber-Institut der Max-Planck-Gesellschaft, Faradayweg 4-6, D-14195, Berlin.

E-mail: thomas@fritz-haber-institut.mpg.de; Fax:+49(0)30 84134401;

Tel: $+49(0) 3084134460$

Received 12th January 2000, Accepted 14th March 2000

\begin{abstract}
Model studies on the catalytic methanol oxidation over single and polycrystalline copper have been performed. The catalytic activity was investigated by means of temperature-programmed techniques (thermal desorption and temperature-programmed reaction spectroscopy, TDS and TPRS, respectively). The TPRS experiments call for the existence of chemically inequivalent species of atomic oxygen accessibly for catalytic processes on the copper surface. The surface morphological changes after the combined action of oxygen and methanol were observed by using atomic force (AFM) and scanning electron miscroscopy (SEM) and indicate the participation of not only the surface but to a great extend also the bulk. Furthermore, ex situ X-ray absorption spectroscopy (XAS) at the $\mathrm{O} \mathrm{K}$-edge shows that a copper suboxide phase of $\mathrm{Cu}_{(x \geqslant 2.5)} \mathrm{O}$ is formed at the surface/near-surface region up to a depth of about $100 \AA$. Core-level (XPS) and valence band (UPS) photoemission suggests that the suboxide phase can be viewed as an oxygen-deficient copper(I) oxide phase exhibiting an increased density-of-states at the Fermi level pointing to an electrically conducting phase. The depth-selective recording of X-ray absorption spectra gives clear evidence of the formation of a protective copper(I) oxide film underneath the suboxide layer covering the bulk metal phase.
\end{abstract}

\section{Introduction}

In the surface science based studies on the methanol oxidation over single crystalline $\mathrm{Cu}(110)$, Wachs and $\mathrm{Madix}^{1,2}$ have shown that the active state of the copper surface for the methanol oxidation was a partially oxidized copper surface exhibiting nucleophilic oxygen adatoms. The oxygen activated the surface for methanol adsorption and removed hydrogen released by water formation on the surface via a low-energy reaction pathway. The resultant overall reaction was at low temperature

$$
2 \mathrm{CH}_{3} \mathrm{OH}+\frac{1}{2} \mathrm{O}_{2} \rightarrow 2 \mathrm{H}_{2} \mathrm{CO}+\mathrm{H}_{2}+\mathrm{H}_{2} \mathrm{O} \text {. }
$$

Additionally, molecular beam and temperature-programmed desorption studies have indicated a temperature depending change in the overall stoichiometry of this reaction. ${ }^{3}$ The slow step in the overall reaction is the breaking of the $\mathrm{C}-\mathrm{H}$ bonds of the methyl group which is thus rate limiting. Furthermore, it was shown by applying surface science techniques that in addition to the well established formation of methoxy species and its subsequent decomposition and desorption as formaldehyde, a second reaction pathway to surface formate, $\mathrm{HCOO}^{-}$, is present. ${ }^{4,5}$ The latter is temperature dependent being undetectable at $260 \mathrm{~K}$ at a $\mathrm{Cu}$ (poly) surface but occurring at a significant rate at $295 \mathrm{~K}$ and above. On the $\mathrm{O}+\mathrm{Cu}(111)$ surface, a minor decomposition path for methanol has been found involving the $\mathrm{CO}_{2}$ formation probably via a formate surface intermediate. ${ }^{5}$ The rate of formaldehyde production is found to be similar for both $\mathrm{Cu}(110)$ and $\mathrm{Cu}$ (poly) surfaces, whereas the rate of formate production is observed to be much faster for the $\mathrm{Cu}$ (poly) surface. Furthermore, it has been shown that the methanol oxidation on an alloy $\mathrm{CuPd}[85: 15](110)$ surface appears to be very similar to that seen on $\mathrm{Cu}(110)$ but the reaction rate of methanol is found to be faster on this alloy surface. ${ }^{6}$
The role of pre-adsorbed oxygen is also of significance since no detectable reaction between methanol and copper surface has been observed by means of surface science. The ability of copper $^{1,2,7}$ and silver ${ }^{8}$ to adsorb methanol dissociatively was found to be greatly enhanced by the presence of adsorbed oxygen species $\left(\mathrm{O}^{*}\right)$ which is called "oxygen-induced adsorption" by Barteau and Madix. ${ }^{9}$ Oxygen atoms adsorbed on Ag surfaces are identified as strong Brønsted bases (proton acceptors) acting as nucleophilic species. The adsorbed oxygen species is thus able to activate heterolytically both $\mathrm{O}-\mathrm{H}$ bonds necessary for the creation of the methoxy species, and $\mathrm{C}-\mathrm{H}$ bonds, leading to compounds with double bonds between carbon and oxygen. Furthermore, Madix and coworkers ${ }^{1,2,9-11}$ have found that formaldehyde is only relatively weakly adsorbed on the $\mathrm{Cu}(110)$ surface and appears to bond through the oxygen end of the molecule. ${ }^{9}$ However, when oxygen is predosed on the surface a much more strongly bound moiety (intermediate species: formate $\left(\mathrm{HCOO}^{-}\right)$) is produced when formaldehyde is subsequently dosed where the adsorbed oxygen species is added to the molecule thus acting electrophilically as a Lewis acid.

This concept helps us to understand that the presence of oxygen is necessary in the feed stream in order to obtain formaldehyde with a $\mathrm{Cu}$ polycrystalline catalyst. The question arises whether adsorbed oxygen species are still present under typical methanol reaction conditions at temperatures around $600 \mathrm{~K}$ in a methanol/air feed gas at atmospheric pressure. Furthermore, it is still an open question if the dehydrogenation and the total oxidation reaction routes occurred, the former one, e.g., catalyzed by nucleophilic strongly bound oxygen species and the latter one catalyzed by electrophilic oxygen species at the copper surface, i.e. oxygen from oxide.

Reports on subsurface $\mathrm{Cu}$-oxygen compounds can be found in the early surface science literature (e.g. ref. 12). UHV studies of oxygen adsorption on single-crystalline copper surfaces 
indicate a "sub-surface" atomic oxygen species: a 4-fold adsorption site coplanar with the top metal atom layer has been found in a low-energy electron diffraction (LEED) study of the $c(2 \times 2) \mathrm{O} / \mathrm{Cu}(100)$ system, ${ }^{13}$ and a long bridge site adsorption with the oxygen atoms about $0.3 \AA$ above the surface on the missing-Cu-row reconstructed $(2 \times 1) \mathrm{O}$ $\mathrm{Cu}(110)$ system has been deduced from a surface extended X-ray absorption fine structure (SEXAFS) study. ${ }^{14}$ Normal photoelectron diffraction at the $c(2 \times 2) \mathrm{O} / \mathrm{Cu}(100)$ system also predicted a 4-fold adsorption site. ${ }^{15} \mathrm{~A}$ 4-fold coordination of oxygen is found at the step edges of the $\mathrm{Cu}(410)$ surface. ${ }^{16,17}$

Oxygen chemisorption on the most reactive $\mathrm{Cu}(110)$ has been studied extensively in the past by a multitude of different experimental techniques: low energy ion scattering spectroscopy (LEISS), ${ }^{18}$ impact collision ion scattering spectroscopy (ICISS), ${ }^{19}$ low energy electron diffraction (LEED) ${ }^{20} \mathrm{X}$-ray diffraction (XRD), ${ }^{21}$ surface extended X-ray absorption fine structure (SEXAFS) ${ }^{22,23}$ and photoelectron diffraction $(\mathrm{PhD}){ }^{24}$ Oxygen chemisorbs dissociatively at $300 \mathrm{~K}$, and a $(2 \times 1)$ LEED pattern is found, corresponding to an oxygen coverage of $\Theta=\frac{1}{2}$ monolayer.

Furthermore, the beginning of the oxide nucleation and growth on copper has been studied recently by using scanning tunneling microscopy (STM) ${ }^{25}$ Exposing the $(2 \times 1)$-reconstructed $\mathrm{Cu}(110)$ surface to much higher amounts of oxygen at $T \geqslant 300 \mathrm{~K}$ induces a second structural transformation, and a LEED pattern changes from $(2 \times 1)$ to a $\mathrm{c}(6 \times 2)$ structure which was found only fully developed after exposure to $\sim 10^{6}$ L (1 L (Langmuir) $=1 \times 10^{-6}$ Torr s) of oxygen. ${ }^{25}$ The oxygen adsorption at $300 \mathrm{~K}$ (and higher temperatures) after the very high oxygen exposure of a $\mathrm{Cu}(110)$ surface is characterized by individual $\mathrm{Cu}$ adatoms (protrusions) on top of the surface which are observed to be highly mobile and, by a "superstructure" that exhibits partially a copper oxide symmetry with oxygen atoms quasi-tetrahedrally and 3-fold coordinated by copper atoms.

It is the purpose of the present work to investigate oxidized copper surfaces with regard to (i) their catalytic activity in the methanol oxidation, (ii) the accompanied surface morphological restructuring and additionally, (iii) the corresponding (near-)surface electronic structure properties. Therefore, preoxidized copper is investigated with temperature-programmed reaction methods (thermal desorption and temperatureprogrammed reaction spectroscopy, TDS and TPRS, respectively) to evaluate the reactivity pattern. The morphological changes on the copper surfaces are investigated by atomic force and scanning electron microscopy, AFM and SEM, in order to obtain information on the restructuring processes. Finally, the (near-)surface-related electronic structure is studied by using X-ray absorption, core-level and valence band photoemission spectroscopy in a depth-selecting mode under clean UHV conditions in order to characterize the copper after quenching the reaction. The copper oxides, $\mathrm{CuO}$ and $\mathrm{Cu}_{2} \mathrm{O}$, serve as reference compounds with a different degree of d-band interaction with oxygen. ${ }^{26}$

\section{Experimental}

In the present TPRS investigations on the catalytic activity of copper, single- and polycrystalline copper samples were oxidized at elevated temperatures of $600 \mathrm{~K}$ and at oxygen pressures of 10 mbar. Subsequently, the samples were treated in methanol (for details see below) in order to reduce the oxide and, additionally, to activate the bulk loaded oxygen for the reaction with methanol molecules adsorbed on the surface. Simultaneously, the temperature of the sample was continuously increased and the product gas composition was detected by conventional mass spectroscopy (MS).

The $\mathrm{Cu}(111)$ single crystal and polycrystalline copper chips showed exactly the same behaviour after performing several reaction cycles. A reaction cycle consisted of a first oxidation treatment at $630 \mathrm{~K}$ for $10 \mathrm{~min}$ with $10 \mathrm{mbar}$ molecular oxygen. After cooling down in oxygen to $300 \mathrm{~K}$ the gas phase is exchanged by a dynamical methanol vapour phase of $10^{-3}$ mbar total pressure. In this atmosphere the sample was heated at $15 \mathrm{~K} \mathrm{~min}^{-1}$ to $800 \mathrm{~K}$. The sample is cooled down in inert gas to $300 \mathrm{~K}$ and a new oxidation cycle was started. All these experiments are performed in an integral reactor device with 5 $\mathrm{g}$ catalyst and purified nitrogen $(99.9999 \%)$ as carrier gas.

AFM and SEM were applied to investigate the morphology on copper surfaces. Polycrystalline copper samples treated as for the TPRS studies were used. In the AFM study the samples were scanned in air with $0.89 \mathrm{~N} \mathrm{~m}^{-1}$ cantilever in the noncontact mode.

The spectroscopic investigations were performed with a modified Leybold LHS 12 MCD system equipped with facilities for UPS, XPS and ion-scattering spectroscopy (ISS). The source for the XPS is the non-monochromatized $\mathrm{Mg} \mathrm{K} \alpha$-line $(1253.6 \mathrm{eV})$ and a fixed analyzer pass energy of $108 \mathrm{eV}$ was used corresponding to an instrumental resolution of $1.0 \mathrm{eV}$. The binding energy (BE) was calibrated using $\mathrm{Au} 4 \mathrm{f}_{7 / 2}$ $(\mathrm{BE}=84.0 \mathrm{eV})$. Surface compositions were calculated after subtraction of a Shirley-type background using the cross sections from Yeh and Lindau. ${ }^{27} \mathrm{He} \mathrm{I}(h v=21.2 \mathrm{eV})$ and $\mathrm{He}$ II $(h v=40.8 \mathrm{eV})$ spectra were acquired using analyzer pass energies of 12 and $24 \mathrm{eV}$, respectively. In order to minimize the sputtering damage, the ISS data were generated using a scanning defocused $1000 \mathrm{eV} \mathrm{He}^{+}$primary beam and a minimized acquisition time of $60 \mathrm{~s}$. The impinging $\mathrm{He}^{+}$current under these quasi-static conditions was about $1 \mu \mathrm{A}$ corresponding to an ion dose of $6 \times 10^{12}$ ions $\mathrm{cm}^{-2} \mathrm{~s}^{-1}$.

The X-ray absorption spectroscopy (XAS) measurements were performed at the SX700-I beamline of the Berliner Synchrotron Radiation source BESSY-I. The synchrotron radiation photon energy ranges from 10 to $2000 \mathrm{eV}$, and the monochromator is operated with a resolution of $1.3 \mathrm{eV}$ at the $\mathrm{O} \mathrm{K}$-edge. The photon energy was calibrated to an accuracy of $\pm 0.5 \mathrm{eV}$ by reference to the La $3 \mathrm{~d} \rightarrow 4 \mathrm{f}$ transition at $836 \mathrm{eV}$ of a $\mathrm{LaAl}_{2}$ sample. The XAS were carried out in a Vacuum Generator double-chamber UHV system with a base pressure of $p \leqslant 1 \times 10^{-10}$ mbar. A VG CLAM100 electron energy analyzer was used for the XAS spectroscopy in the secondaryelectron yield modus $\left(E_{\mathrm{kin}}=8 \mathrm{eV}, E_{\text {pass }}=200 \mathrm{eV}\right)$. A partialelectron yield detector equipped with two commercial multi-channel plates was used for the XAS spectroscopy in the partial-electron yield mode.

Clean $\mathrm{Cu}(111)$ single crystal and polycrystalline copper surfaces were prepared by $\mathrm{Ar}^{+}$-ion bombardment and subsequent annealing at $770 \mathrm{~K}$ until XPS revealed a carbon- and oxygen-free surface. The oxygen exposure up to 10 mbar pressure at high temperature as well as the methanol exposure up to $10^{-4}$ mbar were carried out in a separate reaction chamber mounted on the double-chamber system equipped with a chromel-alumel thermocouple for temperature control. Oxidation of the $\mathrm{Cu}$ foil $(99.98+\%$, Goodfellow) under $1 \mathrm{mbar}$ $\mathrm{O}_{2}(99.998 \%)$ at $670 \mathrm{~K}$ for $2 \mathrm{~h}$ produced a $\mathrm{CuO}$ layer thick enough to conceal the underlying metal from XPS and UV photoelectron spectroscopy (UPS), but thin enough to allow good compensation of charging effects. $\mathrm{Cu}_{2} \mathrm{O}$ was produced by heating $\mathrm{CuO}$ in vacuo at $570 \mathrm{~K}$ for $\sim 1 \mathrm{~h}$ which was checked by means of XPS standard analysis.

\section{Results}

\subsection{Catalytic activity}

In order to analyse the activity of copper for deposition of oxygen in its bulk the following isotope labelling experiment was performed. A sample reacted previously in 60 cycles with ${ }^{16} \mathrm{O}_{2}$ and with methanol is exposed in a TDS UHV apparatus 
at $630 \mathrm{~K}$ for $5 \mathrm{~min}$ to $5 \mathrm{mbar}{ }^{18} \mathrm{O}_{2}$, cooled in UHV and heated in UHV to $1000 \mathrm{~K}$ at $1 \mathrm{~K} \mathrm{~s}^{-1}$. Fig. 1 shows typical results. The oxygen TDS trace for the ${ }^{18} \mathrm{O}_{2}$ species is shown (dashed line). Three distinct desorption features can be seen at $\sim 500, \sim 600$ and $\sim 700 \mathrm{~K}$. All features exhibit isotope scrambling indicating that they all occur from atomic bound states and that no molecular oxygen species is present under these conditions. Only the structured low-temperature peak can be saturated and is ascribed thus to a surface process. The scrambling is complete for the first peak leaving no desorption of pure ${ }^{16} \mathrm{O}_{2}$ which occurs, however, with the two hightemperature desorptions. The structured low-temperature desorption at $\sim 500 \mathrm{~K}$ is ascribed to the decomposition of binary copper oxide films. The sharp feature at about $600 \mathrm{~K}$ is attributed to the desorption of subsurface oxygen and the incomplete desorption to deep bulk-dissolved species. It is noted that these species exchange amongst each other as otherwise the treatment temperature of $630 \mathrm{~K}$ should not have resulted in an isotopic exchange of the high-temperature species which is observed with the same scrambling rate as for the peak at $600 \mathrm{~K}$.

The main reaction channels of oxidative dehydrogenation [eqn. (2)], total oxidation [eqn. (3)] and the decomposition into carbon and water can be followed with the simultaneous detection of water, formaldehyde and carbon dioxide as shown in Fig. 1.

$$
\begin{aligned}
& \mathrm{CH}_{3} \mathrm{OH}+\frac{1}{2} \mathrm{O}_{2} \rightarrow \mathrm{H}_{2} \mathrm{CO}+\mathrm{H}_{2} \mathrm{O} \\
& \mathrm{CH}_{3} \mathrm{OH}+1 \frac{1}{2} \mathrm{O}_{2} \rightarrow \mathrm{CO}_{2}+2 \mathrm{H}_{2} \mathrm{O}
\end{aligned}
$$

The absence of significant effects of heat and mass transport effects can be concluded from the good agreement of the desorption trace with the reaction events. The surface oxygen from oxides, $\mathrm{O}_{(\text {oxi) }}$, leads mainly to unselective total oxidation of methanol, to carbon dioxide and water. The depletion of the subsurface oxygen reservoir leads to a strong decrease in selective oxidation. The oxygen-depleted surface at temperatures above $630 \mathrm{~K}$ is active for decomposition of methanol into carbon and water which results in visible amounts of soot particles at the end of the experiment. This reaction

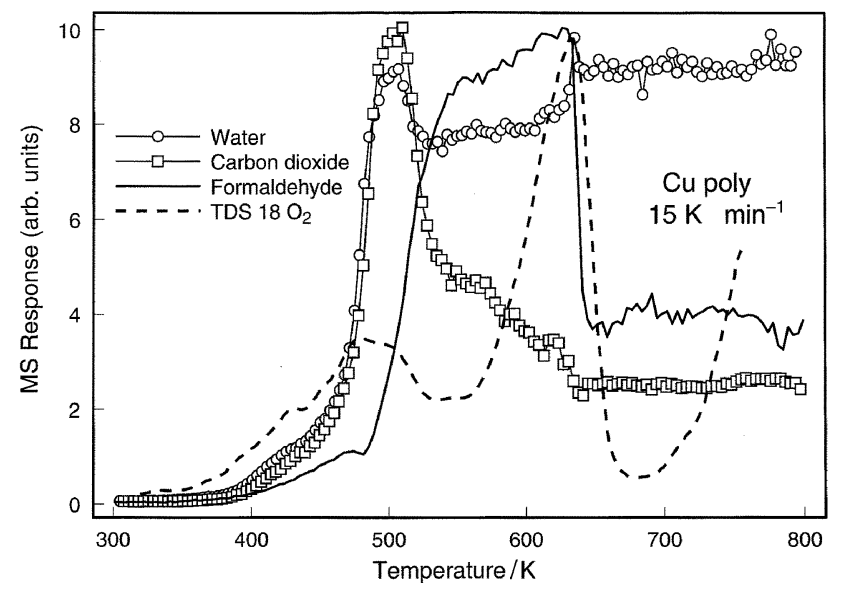

Fig. 1 Results of TDS superimposed with TPRS on pre-oxidized copper are given. The oxygen TDS trace of the ${ }^{18} \mathrm{O}_{2}$ species is shown. Two distinct desorption features can be seen. All three features exhibit isotope scrambling indicating that they occur all from atomic bound states and that no molecular oxygen species is present under these conditions. The structured low-temperature desorption at $\sim 500 \mathrm{~K}$ is ascribed to the decomposition of copper(I) oxide films. The sharp feature at about $600 \mathrm{~K}$ is attributed to the desorption of subsurface oxygen and the incomplete desorption to deep bulk-dissolved species. The main reaction channels of oxidative dehydrogenation (2), total oxidation (3) and decomposition can be followed with the simultaneous detection of water, formaldehyde and carbon dioxide as shown. The surface oxygen from oxides leads mainly to unselective total oxidation of methanol to carbon dioxide and water. pathway should be closed in the steady-state presence of molecular oxygen which will replenish the sub-surface reservoir or even oxidize the surface depending on its partial pressure relative to the methanol abundance.

From a correlation of the water production with the consumption of methanol it appears that the step increase in the water production after desorbing the subsurface oxygen cannot be entirely due to methanol decomposition. It is assumed that during selective oxidation also dehydrogenation [see eqn. (4)] had occurred with the hydrogen produced being stored in the copper metal.

$$
\mathrm{CH}_{3} \mathrm{OH} \rightarrow \mathrm{H}_{2} \mathrm{CO}+\mathrm{H}_{2}
$$

Attempts to quantify these effects with isothermal experiments are unsuccessful due to the equilibration of all reaction channels at temperatures above $500 \mathrm{~K}$. The excess water production decreased with time on stream after stopping the supply with methanol with a time constant 8 times slower than all other gaseous reaction products disappeared. Blank experiments showed that this is not due to the retention of the polar water on the catalyst surface or in the transfer system of the detector.

In summary, the TDS/TPRS-reduction experiments showed the co-existence of a total oxidation reaction pathway at a temperature of about $500 \mathrm{~K}$ working with electrophilic surface oxygen from the oxide, $\mathrm{O}_{(\text {oxi) }}$,

$$
3 \mathrm{Cu}_{2} \mathrm{O}+\mathrm{CH}_{3} \mathrm{OH} \underset{\mathrm{Cu}_{2} \mathrm{O}}{\stackrel{\mathrm{O}_{(\text {oxi) }}}{\longrightarrow}} 6 \mathrm{Cu}+\mathrm{CO}_{2}+2 \mathrm{H}_{2} \mathrm{O}
$$

and the selective oxidative dehydrogenation route at temperatures of about $600 \mathrm{~K}$ working with strongly bound subsurface oxygen, $\mathrm{O}_{(\mathrm{sub})}$, converted to a nucleophilic oxygen surface species, $\mathrm{O}_{(\mathrm{ad})}$,

$$
\mathrm{CH}_{3} \mathrm{OH}+\mathrm{O}_{(\mathrm{ad})} \rightarrow \mathrm{H}_{2} \mathrm{CO}+\mathrm{H}_{2} \mathrm{O} .
$$

Additional evidence is found for the involvement of a third bulk-dissolved oxygen species, $\mathrm{O}_{\text {(bulk) }}$, as a reservoir for the subsurface and surface species and, furthermore, the operation of a dehydrogenation reaction [see eqn. (1)]. The dehydrogenation reaction can be catalyzed by a subsurface oxygen species, $\mathrm{O}_{(\mathrm{sub})}$, that will not be directly consumed during the reaction process due to the detection of $\mathrm{H}_{2}$ in MS:

$$
\mathrm{CH}_{3} \mathrm{OH} \underset{\mathrm{O}_{\text {(sub) }}}{\longrightarrow} \mathrm{H}_{2} \mathrm{CO}+\mathrm{H}_{2} \text {. }
$$

Furthermore, the oxygen-depleted surface at temperatures above $630 \mathrm{~K}$ is active in the methanol decomposition reaction to carbon and water. This concept helps us to understand that the presence of oxygen is necessary in the feed stream in order to obtain formaldehyde with a $\mathrm{Cu}$ polycrystalline catalyst.

\subsection{Morphological changes on the oxidized copper surface}

A strong argument for the involvement of subsurface reaction steps in the catalytic processes of alcohol oxidation is a restructuring process which goes on in parallel with the timeon-stream. The copper catalyst undergoes facetting to an extent that after $60 \mathrm{~h}$ time-on-stream the morphological changes can be seen by eye. This has been also observed for the methanol oxidation to formaldehyde over silver ${ }^{28-31}$ and the ammonia oxidation to nitrogen monoxide over platinum catalysts. $^{32}$

The small size of the modifications required the operation of AFM. Experiments by STM are very difficult due to the presence of a poorly conducting surface layer of the transferred samples. Fig. 2 summarizes typical results. The copper surface is before any treatment only weakly structured with a smooth hill-and-valley morphology interrupted only by scratch marks and deformations from mechanical treatment. 
After oxygen treatment under the conditions described in the previous section 3.1 a block-like morphology is typical with step heights of several tens of nanometres. This indicates already a profound restructuring with participation of bulk processes at the low temperature of $630 \mathrm{~K}$ relative to the melting temperature of copper of $T_{\mathrm{m}}=1360 \mathrm{~K}$. The smooth surface at lower resolution turns out to be covered by small clusters of rough and difficult-to-image character ascribed to oxide particles (see Fig. 2, at the top). These particles are of about spherical shape and cover the top edges of the blocks and to a much lesser extent the terraces. Both surface features disappear after reaction in methanol and oxygen for the short period of one reaction run as seen at the bottom of Fig. 2. The surface is covered by disk-like facets with their basal plane either parallel to the average surface or perpendicular as seen in the image in Fig. 2. At higher resolution these facets appear to result from piles of platelets of about $1 \mathrm{~nm}$ height with regular terraces in between. The random orientation of these features on the macroscopic surface precludes any determination of preferred orientation with averaging diffraction techniques. The clusters of oxide disappear completely. The very rough termination of the individual terraces is seen as indications for their rapid growth. These terraces are also observed by means of SEM in Fig. 3, left. The SEM pictures indicate that the facets appear at the boundaries of the pyramidally formed crystallites grown onto the copper surface (see Fig. 3, right). If the low overall temperature of the treatment is taken into consideration then highly specific subsurface reactions must contribute to this pronounced catalysis-induced restructuring.

An increase of the copper surface up to ten times greater as before activation has also been found in early optical studies. ${ }^{33}$ The data show clearly that the combined action of oxygen and methanol affects not only the copper surface but to a great extent also the bulk. Restructuring over several hundred atomic layers in depth occurred at temperatures of about $0.5 T_{\mathrm{m}}$. In general agreement with the models of metal oxide growth ${ }^{34-36}$ and metal oxide reduction, ${ }^{37,38}$ the AFM and SEM pictures suggest that the combined oxidationreduction treatment is accompanied by a transport of components like copper cations and excess bulk oxygen-in the course of oxidation - and, on the other hand, hydroxyl groups and hydrogen atoms - in the course of reduction - across the growing product overlayer, across its interfaces and, additionally, at the surface. This is in good agreement with the

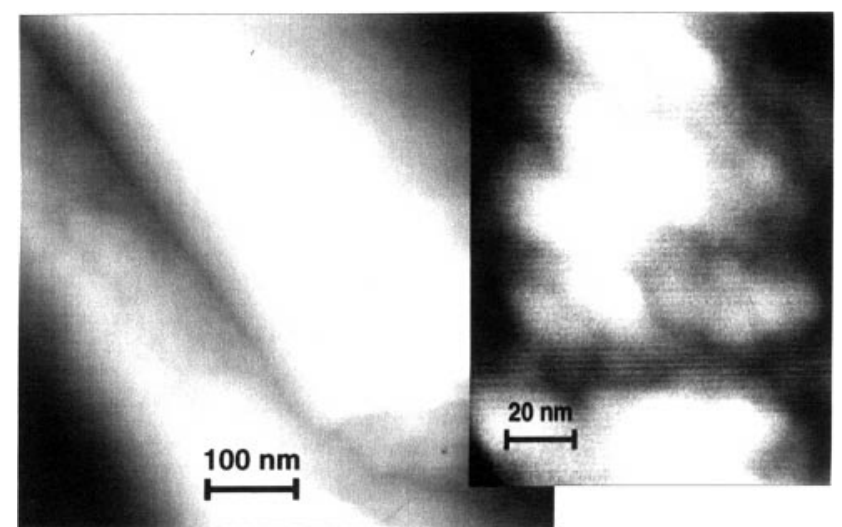

\section{Cu oxidised}

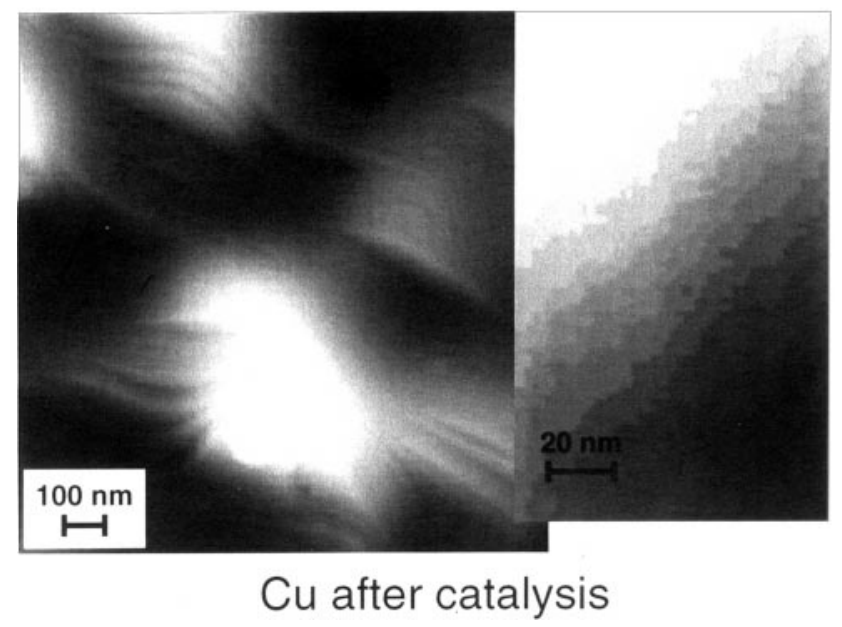

Fig. 2 Atomic force microscope (AFM) pictures are shown. Top: After oxygen treatment the smooth surface at lower resolution turns out to be covered by small clusters of rough and difficult-to-image character ascribed to oxide particles. Bottom: After subsequent methanol treatment, the surface is covered by disk-like facets with their basal plane either parallel to the average surface or perpendicular as seen in the image. At higher resolution these facets appear to result from piles of platelets of about $1 \mathrm{~nm}$ height with regular terraces in between.
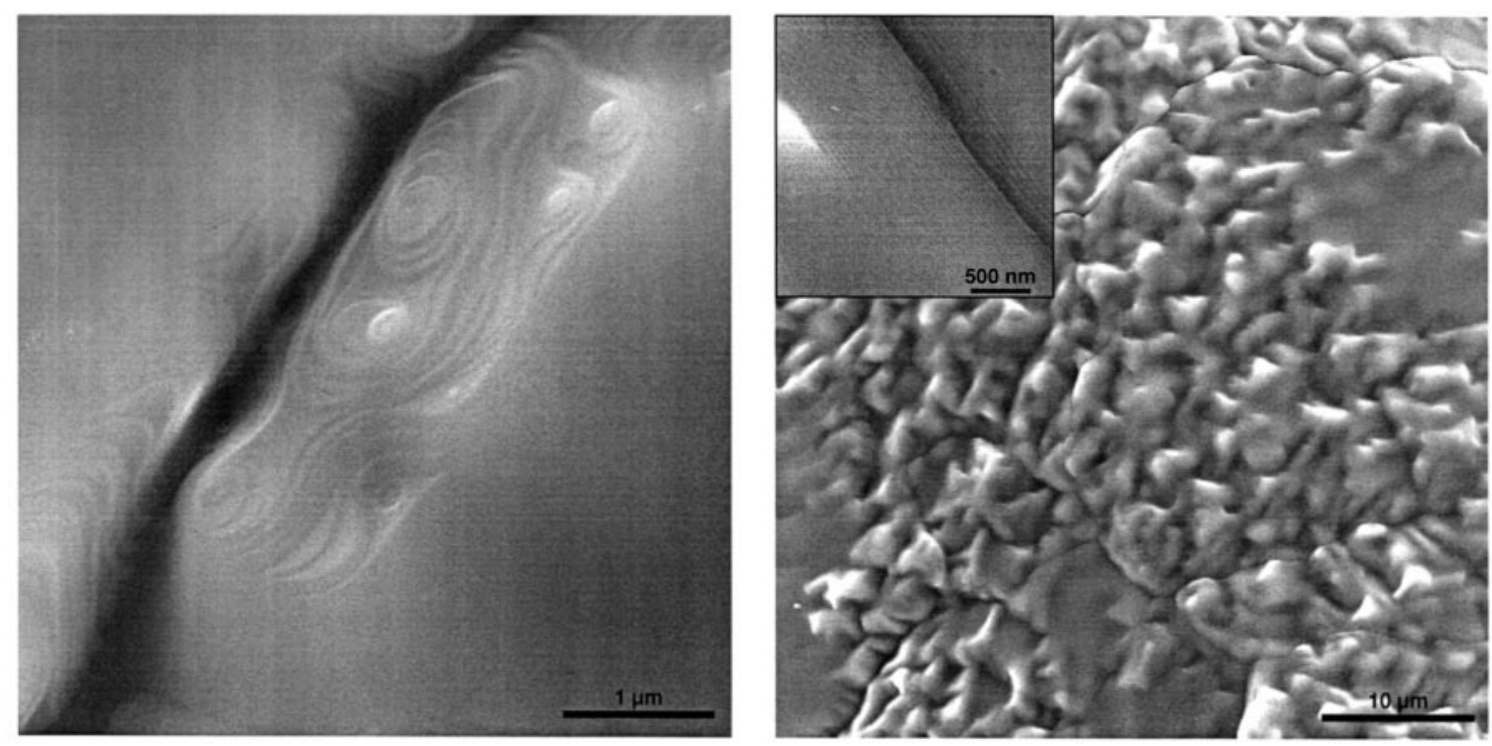

Fig. 3 Scanning electron microscopy (SEM) pictures are shown after exposure to oxygen and subsequent treatment in methanol at $630 \mathrm{~K}$. Left: A facetting of the surface is observed. The SEM picture indicate that the facettes appear at the boundaries of the pyramidally formed crystallites grown onto the copper surface as shown right. 
recent STM observations on the oxygen exposed $\mathrm{Cu}(110)$ surface where a high mobility of copper adatoms was observed. ${ }^{25,39,40}$ Thus, it is not surprising that the observed reconstruction is not restricted to only the surface but comprised also the sub-/near surface and bulk region. Additionally, excess oxygen species formed in the course of the oxidative growth (built-in into the bulk copper(I) oxide lattice at vacant positions: point defect formation, see refs. 34-37), diffuses towards the surface during the oxidative/reductive treatment and can be assigned to the bulk oxygen species. Thus, the question arises concerning a spectroscopic detection of the distinct oxygen species associated with the catalytically active copper phase.

\subsection{X-ray absorption near-edge structures (XANES)}

$\mathrm{X}$-ray absorption spectroscopy is known to be a highly surface sensitive method if applied in the electron-yield mode for low-Z elements in the soft X-ray energy range of $h v \leqslant 1000$ $\mathrm{eV} .{ }^{41}$ In order to estimate the information depth probed by the different electron-yield modii for inorganic compounds, the following equation for the inelastic mean free path (IMFP) $\lambda$ was determined: ${ }^{42}$

$$
\lambda=2170 E_{\mathrm{kin}}^{-2}+0.72\left(a E_{\mathrm{kin}}\right)^{0.5}(\text { monolayers }(\mathrm{ML})),
$$

where $E_{\text {kin }}$ is the kinetic energy of the emitted photoelectron. The monolayer thickness of $\mathrm{Cu}_{2} \mathrm{O}$ is given by

$$
a^{3}=M_{\mathrm{Cu}_{2} \mathrm{O}} /\left(\rho_{\mathrm{Cu}_{2} \mathrm{O}} N_{\mathrm{A}}\right),
$$

where $M_{\mathrm{Cu}_{2} \mathrm{O}}$ is the $\mathrm{Cu}_{2} \mathrm{O}$ molar weight of $143.2 \mathrm{~g} \mathrm{~mol}^{-1}$, $\rho_{\mathrm{Cu}_{2} \mathrm{O}}$ is the $\mathrm{Cu}_{2} \mathrm{O}$ density of $6.0 \mathrm{~g} \mathrm{~cm}^{-3}$, and $N_{\mathrm{A}}$ is the Avogadro number, yielding $a=0.341 \mathrm{~nm}$. For electrons detected in the partial-electron yield (PEY) mode $(-450 \mathrm{~V}$ retarding voltage) at the $\mathrm{O} \mathrm{K}$-edge, $E_{\mathrm{kin}}$ is within the range $450-520 \mathrm{eV}$, yielding an IMFP of $\sim 9$ monolayers $\left(\lambda_{\mathrm{PEY}} \approx 30 \AA\right)$, whereas for electrons measured in the secondary-electron yield (SEY) mode at the $\mathrm{O} \mathrm{K}$-edge, $\mathrm{E}_{\mathrm{kin}}$ is about $8 \mathrm{eV}$, yielding an IMFP of $\sim 35 \mathrm{ML}\left(\lambda_{\mathrm{SEY}} \approx 120 \AA\right)$. The IMFP of about $10 \mathrm{ML}$ for the $\mathrm{O} 1 \mathrm{~s}$ and $\mathrm{Cu} 2 \mathrm{p}$ electrons $\left(E_{\text {kin }}=730\right.$ and $\left.330 \mathrm{eV}\right)$ excited with $1253.6 \mathrm{eV}$ photons ( $\mathrm{Mg} \mathrm{K} \alpha$ radiation) agrees well with that of the electrons detected in the PEY-mode. ${ }^{43}$ Thus, information depths of about 90 and $360 \AA$ are obtained with the PEY and SEY techniques, respectively, but, on the contrary, about $63 \%$ of the totally emitted electron intensity is emitted along a length of $\lambda$. This indicates that the former PEY mode probes mainly the surface and near-surface region up to a depth of about $30-60 \AA$ while the latter SEY mode is more sensitive to the near-surface and bulk region up to a depth of about $120-240 \AA$.

3.3.1 Oxygen treated $\mathrm{Cu}(111)$ surface. Fig. 4 shows the $\mathrm{O}$ $\mathrm{K}$-edge absorption spectrum obtained from $\mathrm{Cu}(111)$ after the exposure to $\mathrm{O}_{2}$ at $1 \mathrm{mbar}$ at $620 \mathrm{~K}$ for $30 \mathrm{~min}$ (Fig. 4a) and, for comparison, the corresponding spectra of copper(II) and copper(I) oxide, $\mathrm{CuO}$ and $\mathrm{Cu}_{2} \mathrm{O}$ (Fig. 4c and d). A synthetic spectrum with weighted contributions from the reference oxides is shown in Fig. $4 b\left[0.4 \mathrm{Cu}_{2} \mathrm{O}+0.6 \mathrm{CuO}\right]$ in order to simulate the experimental spectrum of Fig. 4a. All data are collected in the partial-electron yield mode $(-450 \mathrm{~V}$ retarding voltage) in order to enhance the surface sensitivity to a sampling depth comparable to XPS.

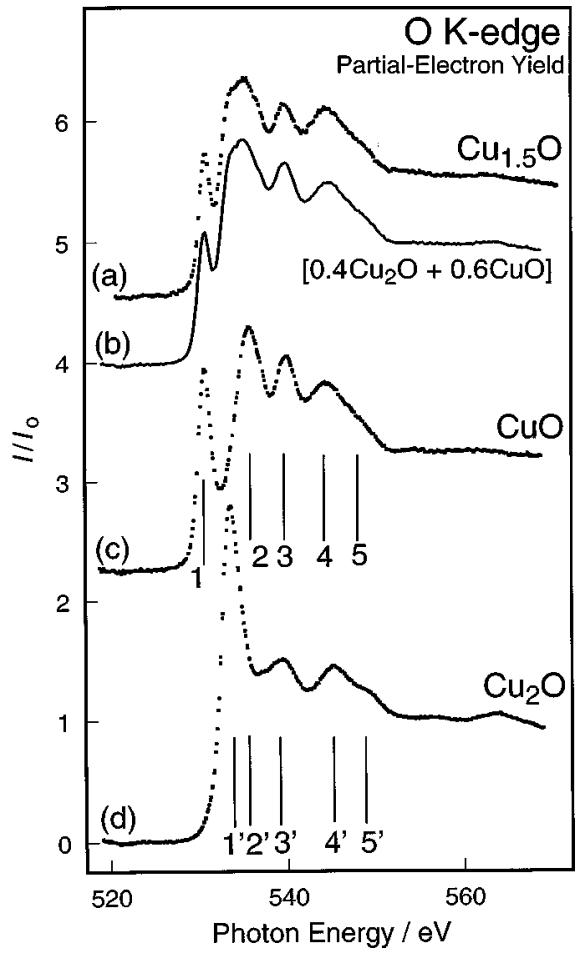

Fig. 4 The $\mathrm{O}$ K-edge X-ray absorption spectra of an oxidized $\mathrm{Cu}(111)$ taken with the partial electron yield mode: (a) after hightemperature treatment at $620 \mathrm{~K}$ in oxygen $(1 \mathrm{mbar})$ for $30 \mathrm{~min}$; (b) a synthetic spectrum with weighted contributions from the reference oxides $\left[0.4 \mathrm{Cu}_{2} \mathrm{O}+0.6 \mathrm{CuO}\right]$; (c) and (d) shows the corresponding spectra of the pristine copper oxides, for comparison. The copper-tooxygen ratio of $x=1.5$ of spectrum (a) is determined with XPS.

In order to discuss the nature of the antibonding states involved in the chemical bonding, one can divide the spectra into two regions: the first region, beginning directly at the threshold near $\sim 531 \mathrm{eV}$ and extending up to $\sim 536 \mathrm{eV}$, is assigned to oxygen $2 p$ admixtures to the states of mainly transition-metal 3d character: the transition-metal $3 \mathrm{~d}$ band. This assignment agrees with molecular orbital calculations. ${ }^{44,45}$ The second region, 5-20 eV above the threshold, is attributed to oxygen $\mathrm{p}$ states hybridized with metal 4sp states. ${ }^{44,45}$ The distribution of oxygen $2 p$ states within this large energy range indicates strong covalent interaction in these oxides. A common structure of the $4 \mathrm{sp}$ band appears in Fig. 3 at $\sim 547 \mathrm{eV}$ photon energy in the spectra of copper oxide. It consists of a double peak separated by $4.0 \mathrm{eV}$. In analogy to the $\mathrm{O} \mathrm{K}$-edges of the other $3 \mathrm{~d}$ transition-metal oxides $^{46}$ this structure can be attributed to the local symmetry determined by nearest (oxygen) neighbors.

The reference oxide data of $\mathrm{Cu}_{2} \mathrm{O}$ and $\mathrm{CuO}$, respectively, are in good agreement with the high-resolution data that exist for $\mathrm{CuO}^{44,45,46,48}$ There is also a general agreement with the available bremsstrahlung isochromat spectroscopic data (BIS) for $\mathrm{CuO}$ and $\mathrm{Cu}_{2} \mathrm{O} .{ }^{45}$ The assignment of the features appearing in the $\mathrm{O} \mathrm{K}$-edge spectra of the two reference oxides, $\mathrm{Cu}_{2} \mathrm{O}$ and $\mathrm{CuO}$, is taken from refs. $46-51$ and is compiled in Table 1.

The spectrum of Fig. 4a reveals the characteristic features of the two reference oxides as shown in Fig. $4 c$ and $d$ and a

Table 1 Assignment of the features appearing in the oxygen $\mathrm{K}$-edge spectra of the two copper oxides, $\mathrm{Cu}_{2} \mathrm{O}$ and $\mathrm{CuO}$ after refs. 46-51

\begin{tabular}{llllll}
\hline \multirow{2}{*}{$\mathrm{Cu}_{2} \mathrm{O}$} & $1^{\prime}: 533.8 \mathrm{eV}$ & $2^{\prime}: 535.7 \mathrm{eV}$ & $3^{\prime}: 539.6 \mathrm{eV}$ & $4^{\prime}: 545.3 \mathrm{eV}$ & $5^{\prime}: 549.3 \mathrm{eV}$ \\
& $\mathrm{O} 2 \mathrm{p} \mathrm{Cu} \mathrm{3d}$ & $\mathrm{O} 2 \mathrm{p} \mathrm{Cu} 3 \mathrm{~d}$ & $\mathrm{O} 2 \mathrm{p} \mathrm{Cu} 4 \mathrm{sp}$ & $\mathrm{O} 2 \mathrm{p} \mathrm{Cu} 4 \mathrm{sp} 4 \mathrm{~d}$ & $\mathrm{O} 2 \mathrm{p} 3 \mathrm{~d} \mathrm{Cu} 4 \mathrm{p} 4 \mathrm{~d}$ \\
$\mathrm{CuO}$ & $1: 530.5 \mathrm{eV}$ & $2: 535.9 \mathrm{eV}$ & $3: 540.0 \mathrm{eV}$ & $4: 544.4 \mathrm{eV}$ & $5: 548.0 \mathrm{eV}$ \\
& $\mathrm{O} 2 \mathrm{p} \mathrm{Cu} \mathrm{3d}$ & $\mathrm{O} 2 \mathrm{p} 3 \mathrm{~d} \mathrm{Cu} 3 \mathrm{~d} 4 \mathrm{~s} 4 \mathrm{p}$ & $\mathrm{O} 2 \mathrm{p} 3 \mathrm{~d} \mathrm{Cu} 3 \mathrm{~d} 4 \mathrm{~s} 4 \mathrm{p}$ & $\mathrm{O} \mathrm{2p} 3 \mathrm{~d} \mathrm{Cu} 4 \mathrm{sp}$ & $\mathrm{O} 2 \mathrm{p} 3 \mathrm{~d} \mathrm{Cu} 4 \mathrm{sp}$ \\
\hline
\end{tabular}


copper-to-oxygen ratio of $(1.5: 1)\left(\mathrm{Cu}_{(x=1.5)} \mathrm{O}\right)$ is determined by the analysis of the corresponding core-level photoemission data for this oxide phase. The sharp pre-peak at $530.5 \mathrm{eV}$ in Fig. 4a can be attributed to only the copper(II) oxide, $\mathrm{CuO}$, (feature 1; see Fig. 4c) while the broader splitted feature at about $536 \mathrm{eV}$ can be assigned to both the copper(I) oxide (shoulder: feature $1^{\prime}$ at $533.8 \mathrm{eV}$; see Fig. 4d) and the copper(II) oxide (feature 2 at $535.9 \mathrm{eV}$; see Fig. 4c). The synthetic spectrum of Fig. $4 \mathrm{~b}$ is in good agreement with the measured oxide spectrum of Fig. 4a indicating that the surface and near-surface region of copper oxide is composed of the two thermodynamically stable copper oxide phases, $\mathrm{Cu}_{2} \mathrm{O}$ and $\mathrm{CuO}$. This is also found by the corresponding $\mathrm{O} 1 \mathrm{~s}$ and $\mathrm{Cu} 2 \mathrm{p}$ core-level spectra of the copper oxide phase of Fig. 4a when compared with the core-level spectra of the reference oxides (not shown). The co-existence of the two copper oxide phases is supported by the fact that mixed crystalline phases of the two stable copper oxides $\mathrm{Cu}_{2} \mathrm{O}$ and $\mathrm{CuO}$ where $\mathrm{Cu}^{2+}$ ions occupy $\mathrm{Cu}^{+}$sites within the $\mathrm{Cu}_{2} \mathrm{O}$ lattice-or vice vers $a$ - are unkown. ${ }^{52}$ On the other hand, it is still an open question whether the $\mathrm{Cu}_{(x=1.5)} \mathrm{O}$ phase represents the paramelaconite phase, $\mathrm{Cu}_{4} \mathrm{O}_{3}$, which is an oxide of copper intermediate between $\mathrm{Cu}_{2} \mathrm{O}$ and $\mathrm{CuO}$. The structure can be described either as derived from the $\mathrm{CuO}$ structure by ordered removal of oxygen atoms or as derived from the $\mathrm{Cu}_{2} \mathrm{O}$ structure by ordered insertion of oxygen atoms. ${ }^{53}$

3.3.2 Oxygen/methanol treated $\mathrm{Cu}(111)$ surface. In order to detect a catalytically active copper-oxygen phase by means of surface sensitive spectroscopic techniques, pre-oxidized copper single crystalline $\mathrm{Cu}(111)$ samples were exposed to methanol at $570 \mathrm{~K}$. The XANES data of the oxygen K-edge were recorded simultaneously in the PEY and SEY modes. The stoichiometric ratio $x$ between copper and oxygen was determined by analysis of the XPS data (see Fig. 5) and is given for each spectrum. ${ }^{54}$

3.3.2.1 Partial-electron yield $O \mathrm{~K}$-edges. Fig. 6 shows a set of $\mathrm{O} \mathrm{K}$-edge spectra recorded after successive treatment of low pressure exposure to methanol $\left(p \approx 5 \times 10^{-6}\right.$ mbar) at $570 \mathrm{~K}$ (Fig. 6b-e). The total methanol dose is given in the unit of Langmuir $\left(1 \mathrm{~L}=1 \times 10^{-6}\right.$ Torr s). Fig. $6 \mathrm{a}$ shows the spectrum of the copper(I) oxide, $\mathrm{Cu}_{2} \mathrm{O}$, for comparison.

It is observed that the indicated chemical composition of the surface and near-surface region as found by XPS is changed up to a total methanol dose of $1.5 \times 10^{5} \mathrm{~L}$ (see Fig.

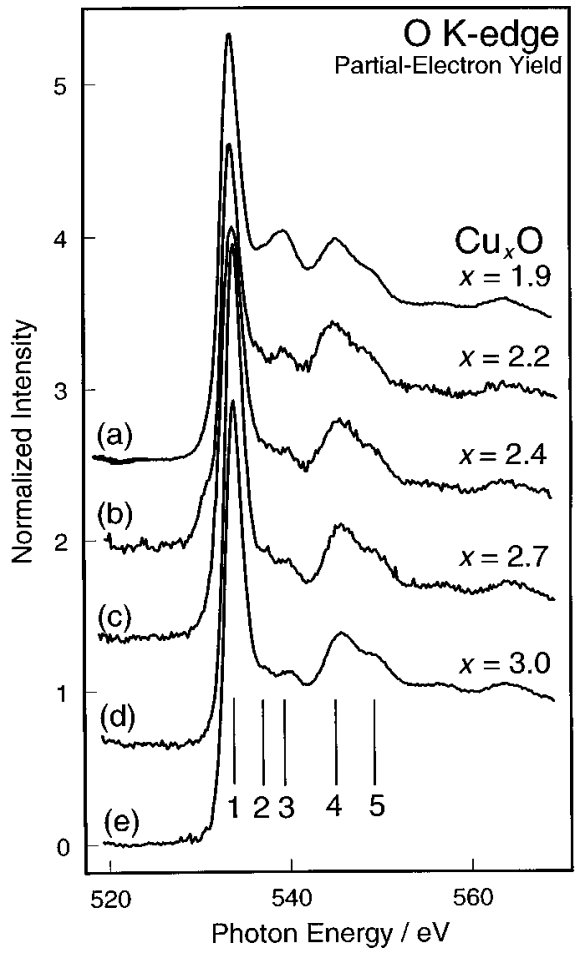

Fig. 6 The $\mathrm{O}$ K-edge X-ray absorption spectra of an oxidized $\mathrm{Cu}(111)$ surface are shown after exposure to methanol at low pressure $\left(5 \times 10^{-6} \mathrm{mbar}\right)$ at $570 \mathrm{~K}$ and taken with the partial-electron yield mode $\left(U_{\text {retarding }}=-450 \mathrm{~V}\right)$. (b) After $1.41 \times 10^{4} \mathrm{~L}$, (c) after $1.0 \times 10^{5}$ $\mathrm{L}$, (d) after $1.5 \times 10^{5} \mathrm{~L}$ and (e) after $2.5 \times 10^{5} \mathrm{~L}(1 \mathrm{~L}=1$ Torr s). The copper-to-oxygen ratio $x$ is determined by XPS as indicated for each spectrum (see Fig. 5). The spectrum of $\mathrm{Cu}_{2} \mathrm{O}$ is also given in (a), for comparison.

6a). Furthermore, only small carbon contamination up to 3 atom $\%$ was found which can be attributed predominantly to initial contamination of the crystal rather than to the formation of intermediate surface species during the gas-solid reaction of methanol with the oxidized copper surface. This is in agreement with the TDS data revealing carbon deposition to occur only above $700 \mathrm{~K}$ (see section 3.1).

The overall shapes of the spectra are in good agreement with the corresponding spectrum of the copper(I) oxide (Fig. 6a). The spectra consist of a strong, sharp feature 1 at 533.8

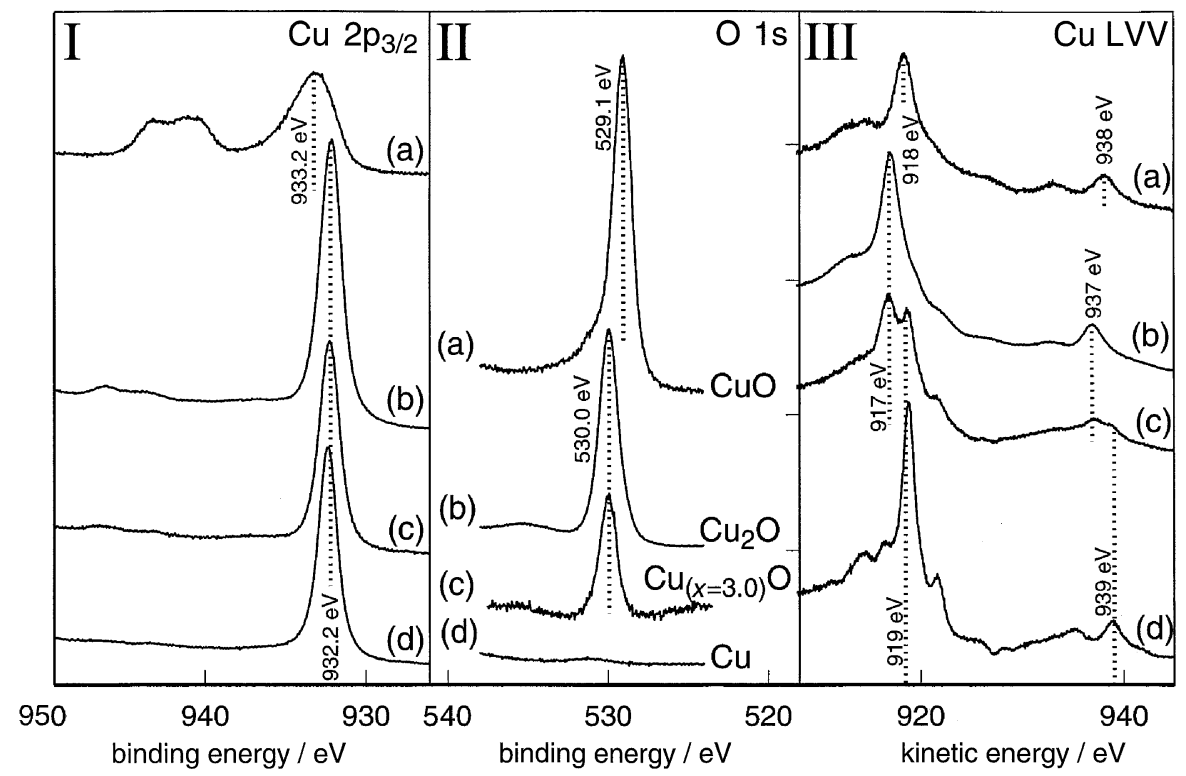

Fig. 5 The $\mathrm{Cu} 2 \mathrm{p}$ and $\mathrm{O}$ 1s core-level spectra and the corresponding $\mathrm{Cu}$ LVV Auger electron spectra of the $\mathrm{Cu}_{(x=3.0)} \mathrm{O}$ suboxide phase, (c), the reference oxide phases of $\mathrm{Cu}_{2} \mathrm{O}$ and $\mathrm{CuO}$, (a), (b) and the copper metal, (d) are given in I, II, and III, respectively. 
$\mathrm{eV}$ (white line) and of smaller features labelled 2-5 which appear at higher photon energy. The white line of the spectrum of Fig. $6 \mathrm{~b}$ (methanol dose: $1.41 \times 10^{4} \mathrm{~L}$ ) is preceded by a shoulder at about $531 \mathrm{eV}$ which can be attributed to copper(II) oxide since it is concordant with the energetic position of the sharp feature in the corresponding spectrum of $\mathrm{CuO}$ (see Fig. 4c, feature 1). This small feature disappears totally after a total methanol dose of $1.5 \times 10^{5} \mathrm{~L}$ (see Fig. $6 \mathrm{~d}$ ) which points to the existence of a single oxide-like phase at the surface and near-surface region after the reduction of small $\mathrm{CuO}$ contributions. In contrast to the genuine copper(I) oxide, an increased copper-to-oxygen ratio of $x=2.2$ (Fig. 6c) up to $x=3.0$ (Fig. 6d and e) is observed which indicates that the oxygen content is lowered within the probed surface and nearsurface region after the high temperature methanol treatment.

A closer inspection of the spectral overall shapes and the intensities of features 1-5 of Fig. 6 suggests that the intensities of white line 1 at $533.8 \mathrm{eV}$ and feature 3 depend on the total methanol dose. The assignment of the features of the $\mathrm{Cu}_{(x=3.0)} \mathrm{O}$ phase is followed by the corresponding spectral assignment of copper(I) oxide. Thus, the white line is assigned to an $\mathrm{O} 1 \mathrm{~s} \rightarrow \mathrm{O} 2 \mathrm{p} \mathrm{Cu} 3 \mathrm{~d}$ transition (see Table 1; refs. 37 and 38) while feature 3 is due to a transition of an $\mathrm{O} 1$ s electron into the unoccupied $\mathrm{O} 2 \mathrm{p} \mathrm{Cu} 4 \mathrm{sp}$ states. ${ }^{49,50}$

The white line intensity increases continuously in the spectra of Fig. 6c-e (referred to $\mathrm{Cu}_{2} \mathrm{O}$ ) while, simultaneously, the intensity of the broad feature 3 at $539.6 \mathrm{eV}$ decreases continuously in the spectra of Fig. $6 \mathrm{c}-\mathrm{e}$ (also referred to $\mathrm{Cu}_{2} \mathrm{O}$ ). The broader features at 545.3 and $549.3 \mathrm{eV}$ are attributed to transitions of an $\mathrm{O} 1 \mathrm{~s}$ electron into the unoccupied $\mathrm{O} 2 \mathrm{p} \mathrm{Cu}$ $4 \mathrm{sp} 4 \mathrm{~d}$ (feature 4) and $\mathrm{O} 2 \mathrm{p} 3 \mathrm{~d} \mathrm{Cu} \mathrm{4p4d} \mathrm{(feature} \mathrm{5)} \mathrm{bands.}{ }^{49,50}$ It is found that these features are almost unchanged during the methanol treatment. ${ }^{55}$

An outstanding point in the (near-)surface copper suboxide spectra of Fig. 6 is the modification of the spectral shape between the unoccupied $\mathrm{O} 2 \mathrm{p} \mathrm{Cu} 3 \mathrm{~d}$ covalent band at 533.8 $\mathrm{eV}$ (white line, feature 1) and the $\mathrm{O} 2 \mathrm{p} \mathrm{Cu} 4 \mathrm{sp}$ derived covalent band (feature 3) at $539.6 \mathrm{eV}$ which depends on the total methanol dose. Concurrent with the increased abundance of copper relative to oxygen the number of $\mathrm{Cu} 3 \mathrm{~d}$ states available for mixing with $\mathrm{O} 2 \mathrm{p}$ states (hybridization) grows while, on the other hand, the number of $\mathrm{Cu} 4 \mathrm{sp}$ states available for mixing with $\mathrm{O} 2 \mathrm{p}$ states falls. This can be due to the observed structural surface morphological modifications at the surface and near-surface region and, subsequently, a corresponding change in the copper-to-oxygen coordination number in the course of the oxidative and subsequent reductive treatment.

3.3.2.2 Secondary-electron yield $O \mathrm{~K}$-edges. Fig. 7 shows a set of O K-XANES spectra (Fig. 7b-e) taken in the SEY mode which were simultaneously recorded with the PEY spectra of Fig. 6. The simultaneous detection of the secondary emitted electrons with about $8 \mathrm{eV}$ kinetic energy is used to obtain near-surface and bulk-related absorption spectra.

In analogy to the PEY O K-XANES spectra of Fig. 6, the spectral overall shape of the O K-XANES spectra detected in the SEY mode resembles that of the copper(I) oxide spectrum shown in Fig. 7a, for comparison. The white line (feature 1) of the spectrum of Fig. $7 \mathrm{~b}$ (methanol dose: $1.41 \times 10^{4} \mathrm{~L}$ ) is preceded by a small peak at about $531 \mathrm{eV}$ which can be attributed to small contributions of copper(II) oxide since the energy position is concordant with the energy position of the sharp feature 1 in the spectrum of $\mathrm{CuO}$ (see Fig. 4c). This small feature disappears after reduction with a methanol dose of $1.5 \times 10^{5} \mathrm{~L}$ (see Fig. 7c) which points to the reduction of the $\mathrm{CuO}$ proportions in the near-surface/bulk region as observed also in the (near-)surface region. ${ }^{56}$ In contrast to the (near-) surface-related PEY spectra of Fig. 6, the intensity of the white line at $533.7 \mathrm{eV}$ of the near-surface/bulk-related SEY spectra remains almost constant during the methanol treatment and agrees well with the corresponding intensity of the

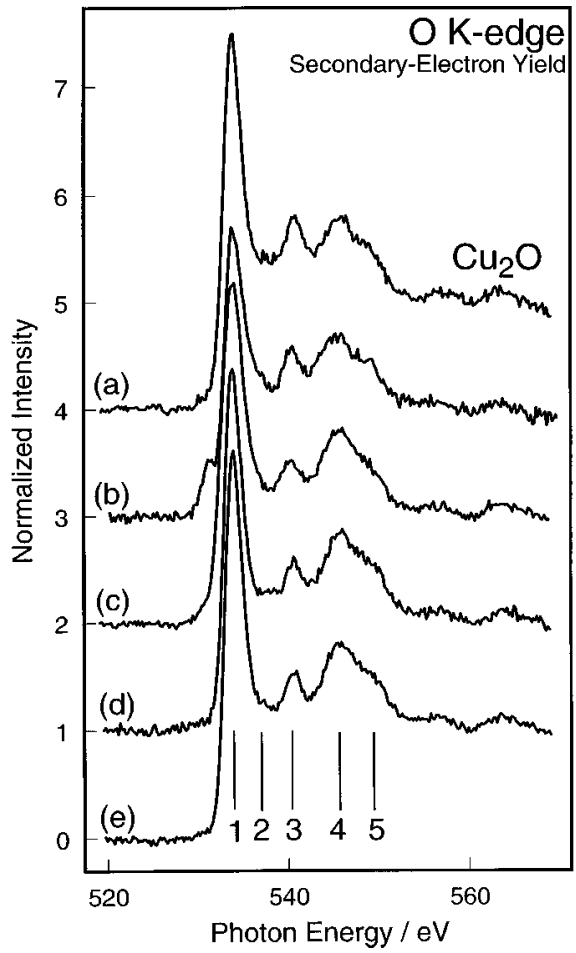

Fig. 7 The $\mathrm{O}$ K-edge X-ray absorption spectra of an oxidized $\mathrm{Cu}(111)$ surface are shown after exposure to methanol at low partial pressure $\left(5 \times 10^{-6} \mathrm{mbar}\right)$ at $570 \mathrm{~K}$ and taken with the secondaryelectron yield mode $\left(E_{\mathrm{kin}}=8 \mathrm{eV}\right)$. The spectra were detected simultaneously with the corresponding partial-electron yield spectra of Fig. 5 . (b) After $1.41 \times 10^{4} \mathrm{~L}$, (c) after $1.0 \times 10^{5} \mathrm{~L}$, (d) after $1.5 \times 10^{5} \mathrm{~L}$ and (e) after $2.5 \times 10^{5} \mathrm{~L}\left(1 \mathrm{~L}=1\right.$ Torr s). The spectrum of $\mathrm{Cu}_{2} \mathrm{O}$ is also given in (a), for comparison.

white line of the copper(I) oxide spectrum of Fig. 7a while feature 3 at $540.5 \mathrm{eV}$ exhibits a smaller intensity (decrease: $\sim 30 \%$ ) referred to the features of $\mathrm{Cu}_{2} \mathrm{O}$.

The XANES data taken with the SEY mode are related to the near-surface and bulk region of the copper-oxygen solid state phase (information depth $\sim 360 \AA$ ) and show the formation of an adherent copper(I) oxide film covering the copper metal as also indicated by means of XRD. ${ }^{5758}$ Thus, the copper oxide phase found in the near-surface/bulk region reveals a very similar copper-to-oxygen bonding interaction between the oxygen $2 p$ and copper $3 d / 4$ sp states if compared with the copper(I) oxide phase. The thin protective oxide film itself is covered by an ultrathin suboxide film, $\mathrm{Cu}_{(x \geqslant 2.5)} \mathrm{O}$, created during the reduction treatment with methanol.

\subsection{Valence band photoemission}

A set of angle-integrated valence band spectra of oxidized copper surfaces excited by He I $(h v=21.2 \mathrm{eV})$ and He II $(h v=40.8 \mathrm{eV})$ radiation are shown in Figs. 8 and 9, respectively. The spectra (a) of copper metal $(\mathrm{Cu}),(\mathrm{b})$ of copper(I) oxide $\left(\mathrm{Cu}_{2} \mathrm{O}\right)$, (c) of copper(II) oxide $(\mathrm{CuO})$, (d) and (e) of preoxidized and subsequently reduced $\mathrm{Cu}(111)$ and $\mathrm{Cu}$ (poly) (preoxidized in $1 \mathrm{mbar}_{2} \mathrm{O}_{2}$ at $620 \mathrm{~K}$ for $30 \mathrm{~min}$ and subsequently exposed to $2.5 \times 10^{5} \mathrm{~L}$ methanol at $570 \mathrm{~K}$ ), respectively, are shown. The binding energy (BE) is plotted relative to the Fermi level. The stoichiometric ratio $x$ between copper and oxygen was determined by the analysis of the corresponding core-level photoemission data (not shown) and is given for each spectrum.

The atomic cross-section ratios, weighted by the number of electrons per (isolated) atom, are $\sigma(\mathrm{O} 2 \mathrm{p}) / \sigma(\mathrm{Cu} 3 \mathrm{~d}) \approx 1.4$ and 0.7 for $h v=21.2 \mathrm{eV}(\mathrm{He} \mathrm{I})$ and $h v=40.8 \mathrm{eV}$ (He II), respectively. ${ }^{27}$ In the $21.2 \mathrm{eV}$ excited spectra one can see therefore mainly the $\mathrm{O} 2 \mathrm{p}$ spectral weight which is concentrated below 


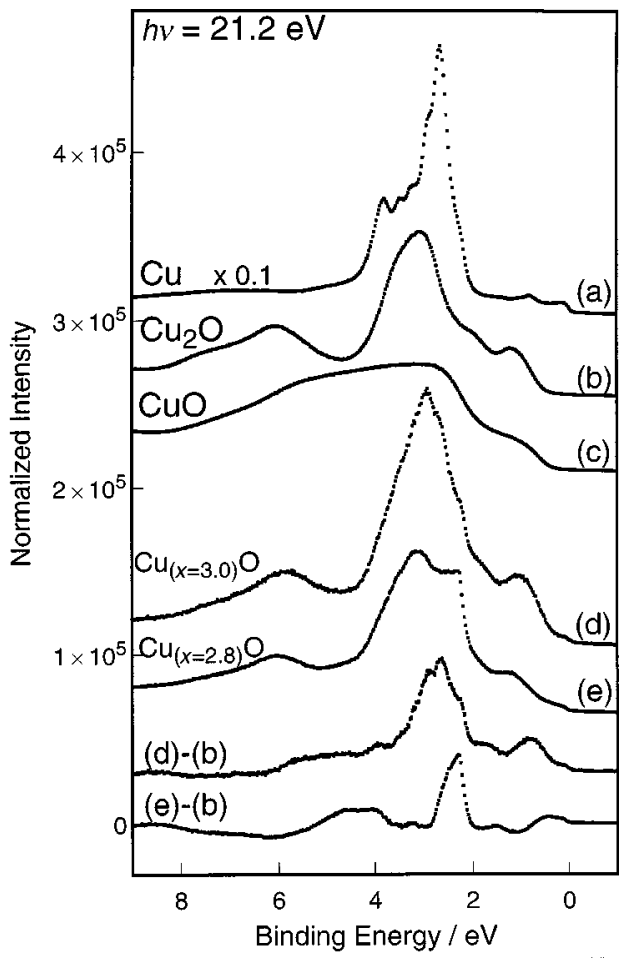

Fig. 8 A set of angle-integrated valence band spectra of oxidized copper surfaces excited by He I $(h v=21.2 \mathrm{eV})$ radiation is shown. The spectra (a) of metal $\mathrm{Cu}(111)$, (b) of copper(I) oxide, (c) of copper(II) oxide, (d) and (e) of the copper suboxides [pre-oxidized in 1 mbar $\mathrm{O}_{2}$ at $620 \mathrm{~K}$ for $30 \mathrm{~min}$ and subsequently exposed to $2 \times 10^{5} \mathrm{~L}$ methanol at $570 \mathrm{~K}$; (d): $\mathrm{Cu}(111)$ and (e): $\mathrm{Cu}($ poly)] are shown. The binding energy (BE) is plotted relative to the Fermi level. On the bottom, the difference spectra between the suboxides (d), (e) and the copper(I) oxide, (b), are given. The stoichiometric ratio $x$ between copper and oxygen is determined by analysis of the corresponding core-level photoemission data (Fig. 5) and is given for each spectrum.

and above the $\mathrm{Cu} 3 \mathrm{~d}$-derived bands-located at $\sim 3 \mathrm{eV} \mathrm{BE}-$ between the Fermi level and $2.5 \mathrm{eV}$ and between 6.0 and 8.0 eV BE, respectively. ${ }^{59}$ The main $\mathrm{Cu} 3 \mathrm{~d}$ spectral weight is concentrated around $3.0 \mathrm{eV} \mathrm{BE}$ but one observes $\mathrm{Cu} 3 \mathrm{~d}$-derived emissions in the $40.8 \mathrm{eV}$ excited spectra also below and above this dominant $\mathrm{Cu} 3 \mathrm{~d}$-emission at $\sim 1.5 \mathrm{eV}$ and between 6.0 and $8.0 \mathrm{eV}$, respectively, due to the covalent interaction between the $\mathrm{Cu} 3 \mathrm{~d}$ and the $\mathrm{O} 2 \mathrm{p}$ states. The difference spectra between the methanol reduced copper oxide spectrum and the copper(I) oxide spectrum, (d)-(b) and (e)-(b), respectively, are also given at the bottom of Figs. 8 and 9 in order to show the different chemical interaction between copper and oxygen in the novel copper suboxide (near-)surface phase of $\mathrm{Cu}_{(x \geqslant 2.8)} \mathrm{O}$. These difference spectra give clear evidence for extra emission bands from the suboxide phase appearing directly at the Fermi level, at $\sim 0.7$ and $\sim 2.5 \mathrm{eV}$, respectively, and, additionally, in the range between 4 and $5.5 \mathrm{eV}$. The extra $2.5 \mathrm{eV}$ emission in the suboxide spectra can be attributed to copper metal $\mathrm{Cu} 3 \mathrm{~d}$ states while the other emission lines appearing in the difference spectra can be assigned to neither the oxide nor the metal phase. This supports the formation of a novel suboxide phase in the (near-)surface region which is not simply a co-existing 2-phase system composed of copper metal and copper(I) oxide.

A comparison of the stoichiometry of the copper(I) oxide, $\mathrm{Cu}_{2} \mathrm{O}$, with the novel (near-)surface copper suboxide phase, $\mathrm{Cu}_{(x \geqslant 2.5)} \mathrm{O}$, indicates a formal valence shell configuration of copper of $\left([\mathrm{Ar}] 3 \mathrm{~d}^{10} 4 \mathrm{~s}^{0}\right)$ for $\mathrm{Cu}_{2} \mathrm{O}$ and of $\left([\mathrm{Ar}] 3 \mathrm{~d}^{10} 4 \mathrm{~s}^{0.33}\right)$ for $\mathrm{Cu}_{(x=3.0)} \mathrm{O}$. This suggests that the copper suboxide phase should exhibit an increased density-of-states of occupied $\mathrm{Cu}$ $4 \mathrm{~s}$ states at the Fermi level and, thus, an enhanced metallic character. This is in full agreement with the valence band

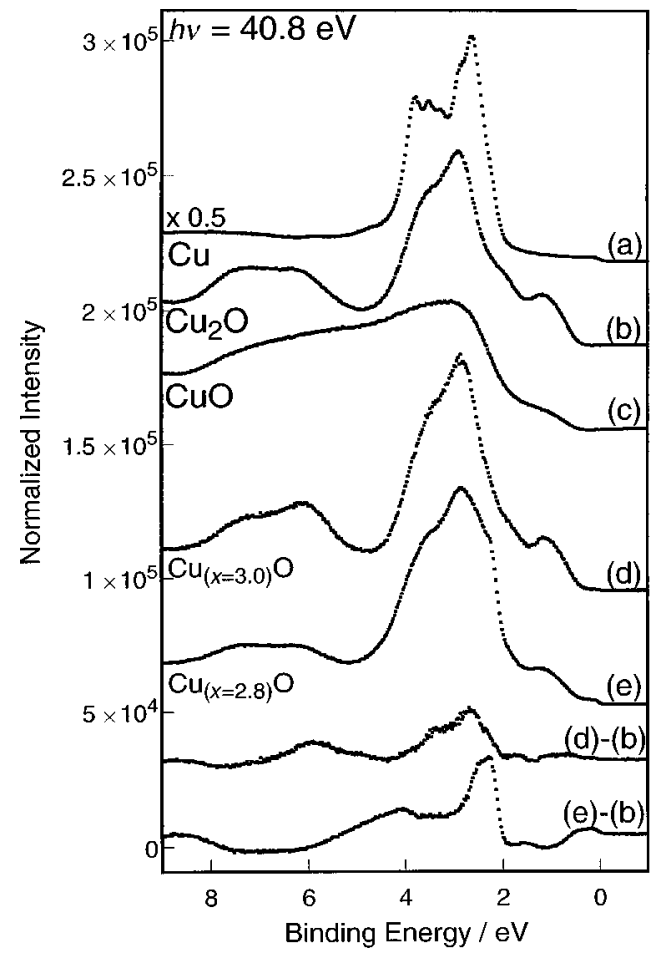

Fig. 9 A set of angle-integrated valence band spectra of oxidized copper surfaces excited by He II $(h v=40.8 \mathrm{eV})$ radiation is shown. The spectra (a) of metal $\mathrm{Cu}(111)$, (b) of copper(I) oxide, (c) of copper(II) oxide, (d) and (e) of the copper suboxides [pre-oxidized in $1 \mathrm{mbar}_{2}$ at $620 \mathrm{~K}$ for $30 \mathrm{~min}$ and subsequently exposed to $2 \times 10^{5} \mathrm{~L}$ methanol at $570 \mathrm{~K}$; (d): $\mathrm{Cu}(111)$ and (e): $\mathrm{Cu}($ poly)] are shown. The binding energy (BE) is plotted relative to the Fermi level. On the bottom, the difference spectra between the suboxides (d), (e) and the copper(I) oxide, (b), are given. The stoichiometric ratio $x$ between copper and oxygen is determined by analysis of the corresponding core-level photoemission data (Fig. 5) and is given for each spectrum.

spectra of the single and polycrystalline copper oxide surfaces as shown in Figs. 8 and 9 where an extra emission at the Fermi level referred to copper(I) oxide is observed due to an increased $\mathrm{Cu} 4 \mathrm{~s}$-derived density-of-states. The number of $\mathrm{Cu}$ atoms of the suboxide phase, $\mathrm{Cu}_{(x \geqslant 2.5)} \mathrm{O}$, are enhanced when compared with the copper(I) oxide, $\mathrm{Cu}_{2} \mathrm{O}$, suggesting an increase of the oxygen coordination by copper atoms and, subsequently, also an increase of the surface free energy of the novel copper suboxide phase in relation to the copper(I) oxide surface. This new copper-to-oxygen bonding arrangement at the surface induces a modified $\mathrm{Cu}$-to-O covalent interaction in relation to $\mathrm{Cu}_{2} \mathrm{O}$, which leads to an alteration in the $\mathrm{O} 2 \mathrm{p}-\mathrm{Cu}$ $3 \mathrm{~d}$ and $\mathrm{O} 2 \mathrm{p}-\mathrm{Cu} 4 \mathrm{sp}$ orbital interaction.

In a model of the binding mechanism in $\mathrm{Cu}_{2} \mathrm{O}$, unoccupied $\mathrm{Cu} 3 \mathrm{~d}_{z^{2}}$ contributions to the conduction band hybridize with O $2 \mathrm{p}$ states to form $\mathrm{pd} / \mathrm{pd}^{*}$ bonds with $\sigma$ and $\pi$ character. ${ }^{59}$ Furthermore, an earlier model of Orgel explained the linear coordination of $\mathrm{Cu}^{+}$and $\mathrm{Ag}^{+}$in the binary oxides by assuming $\mathrm{s}-\mathrm{d}_{z^{2}}$ hybridization. ${ }^{60}$ This hybridization at the copper and silver cation removes electrons from the bond $z$ axis, spreads them in the diffuse $4 \mathrm{~s}$ orbitals, and permits the oxygen anions to approach much closer than the sum of the ionic radii. The hybrid orbital $\left[\alpha \Psi\left(\mathrm{d}_{z^{2}}\right)+\beta \Psi(\mathrm{s})\right]$, of symmetry $\mathrm{a}_{1 \mathrm{~g}}$, is more effective in the charge depletion at the distances from $\mathrm{Cu}^{+}$larger than about $0.8 \AA$ if $\beta / \alpha$ is negative. Nagel ${ }^{61}$ has computed a hybridization of $\beta / \alpha \approx-1 / 2$. The valence band and $\mathrm{O} \mathrm{K}$-edge $\mathrm{X}$-ray absorption data of the (near-) surface suboxide phase, $\mathrm{Cu}_{(x \geqslant 2.5)} \mathrm{O}$, indicate that as for copper(I) oxide the $\mathrm{Cu}-\mathrm{O}$ bonding can be interpreted in terms of a molecular orbitals (MO) picture. As in the cluster-model of $\mathrm{Cu}_{2} \mathrm{O}$ from Marksteiner et al., ${ }^{59}$ unoccupied $\mathrm{O} 2 \mathrm{p} \mathrm{Cu} 3 \mathrm{~d}$ contributions are observed at the bottom of the conduction 
band $(\mathrm{CB})$ while the $\mathrm{O} 2 \mathrm{p} \mathrm{Cu} 4 \mathrm{sp}$-derived contributions to the $\mathrm{CB}$ are observed at higher energies. The latter contributions are partly reduced in the suboxide phase and, consequently, enhanced occupied $\mathrm{Cu} 4$ sp-derived contributions to the valence band (VB) are observed in the VB photoemission of the $\mathrm{Cu}_{(x \geqslant 2.8)} \mathrm{O}$ phase. The delocalized electrons in the $\mathrm{Cu} 4 \mathrm{~s}$ bands can be the driving force for a stabilization of the $\mathrm{Cu}_{(x \geqslant 2.8)} \mathrm{O}$ suboxide phase at the (near-)surface.

\section{Discussion and summary}

Single and polycrystalline copper samples are oxidized to a 2-phase mixture composed of copper(I) and copper(II) oxide and afterwards, are exposed to methanol (maximum dose of $2.5 \times 10^{5} \mathrm{~L}$ ) at about $600 \mathrm{~K}$. An enlarged copper surface was found ex situ after the exposure to oxygen and methanol at elevated temperatures $\left(\frac{1}{2} T_{\mathrm{m}} \approx 680 \mathrm{~K}\right)$ where the combined action of oxygen and methanol affects not only the copper surface but to a great extent also the bulk. The surface morphological observations indicate the formation of a network of pyramidal grains in the course of the gas/solid state reaction at the contact surface. This is important for the oxygen back-diffusion process from the bulk to the (near-)surface region since the diffusion of oxygen atoms through the interstitial sites or voids of the close-packed copper crystal can be hindered $^{62}$ and, hence, the oxygen transport pathways from the bulk to the surface can be provided also by the grain boundary network.

The existence of chemically inequivalent species of atomic oxygen accessible for catalytic processes on the copper surface have been observed during the methanol treatment of a preoxidized copper surface in situ by TPRS superimposed with TDS. The co-existence of a total oxidation reaction channel at a temperature of about $500 \mathrm{~K}$ is found working with electrophilic oxygen from the oxide, $\mathrm{O}_{(\text {oxi) }}$, while the selective oxidative dehydrogenation reaction pathway is observed at temperatures of about $600 \mathrm{~K}$ working with nucleophilic surface oxygen species, $\mathrm{O}_{(\mathrm{ad})}$. There is evidence for the segregation of bulk oxygen, $\mathrm{O}_{(\text {bulk })}$, towards the surface which can be converted to both a nucleophilic subsurface oxygen, $\mathrm{O}_{(\mathrm{sub})}$, acting as Brønsted base (proton acceptor) and catalyzing the dehydrogenation reaction pathway and a nucleophilic surface oxygen species, $\mathrm{O}_{(\mathrm{ad})}$, catalyzing the oxidative dehydrogenation reaction pathway and acting also as Brønsted base.

In general, when the oxygen molecule has been dissociated at the copper surface, the oxygen adatoms are able to segregate to subsurface and near-surface positions. This can be the beginning of near-surface and bulk oxidation, when thermodynamics favors the oxide formation. The formation of a copper suboxide phase, $\mathrm{Cu}_{(x \geqslant 2.5)} \mathrm{O}$ was observed ex situ, i.e. after the exposure of pre-oxidized single and polycrystalline copper surfaces to methanol at high temperatures. The suboxide phase is detected at the surface and near-surface region up to a depth of about $100 \AA$ and can be described as thermodynamically stable copper-rich solid state phases. There is also an indication of the co-existence of a copper metal and a copper(I) oxide phase at the (near-)surface region. The prepared suboxide phase is only analytically accessible to surface sensitive spectroscopic detection techniques excluding, on the other hand, any reasonable bulk analytical characterization in the sense of an overall stoichiometric formula.

Underneath the copper suboxide phase of $\mathrm{Cu}_{(x \geqslant 2.5)} \mathrm{O}$, a copper(I) oxide, $\mathrm{Cu}_{2} \mathrm{O}$, film was found ex situ up to a depth of about $400 \AA$ representing an adherent (protective) product layer covering the bulk copper metal. The protective copper oxide film is created by segregation of the surface oxygen species, $\mathrm{O}_{(\mathrm{ad})}$, to the sub- and near-surface region and, additionally, by back-diffusion of bulk dissolved oxygen species, $\mathrm{O}_{\text {(bulk) }}$, to the (near-)surface region. The copper concentration of the (near-)surface-related suboxide phase, $\mathrm{Cu}_{(x \geqslant 2.5)} \mathrm{O}$, is enhanced if compared with the protective $\mathrm{Cu}_{2} \mathrm{O}$ film found underneath due to the reduction treatment of the copper(I) oxide phase by methanol molecules. The above results are summarized within a schematic diagram (Fig. 10) showing the connection between the different oxygen species and the assumed $\mathrm{Cu}$-to-O ratios.

The minimization of the surface free energy of a solid state phase can be viewed as the driving force for the formation of a (sub-)oxide phase onto the copper metal as found ex situ. The increased penetration of adsorbed oxygen species, $\mathrm{O}_{(\mathrm{ad})}$, deeper into the lattice (alternatively: enhanced copper cation diffusion to the surface in the course of the oxide film growth) reduces the total energy of the copper metal solid state phase, and, thus, results in a thermodynamically stable phase at room temperature. Generally, the metal surfaces reveals an almost oxidic property induced by an increase of the temperature and/or the chemical potential of oxygen and the onset of copper(I) oxide film growth is observed. The formation of a thermodynamically stable (sub-)oxide is favoured due to an intensification of the orbital interaction between oxygen and copper atoms. The oxide formation is accompanied by an additional increase of the oxygen-to-copper covalent interaction from $\mathrm{O} 2 \mathrm{p}-\mathrm{Cu} 4 \mathrm{sp}$ to $\mathrm{O} 2 \mathrm{p}-\mathrm{Cu} 4 \mathrm{sp}$ and $\mathrm{O} 2 \mathrm{p}-\mathrm{Cu} 3 \mathrm{~d}$ as found ex situ in the oxide and suboxide phase. This can be viewed as a consequence of further reduction of the $\mathrm{Cu}-\mathrm{Cu}$ coordination number in the oxide and suboxide phase where the splitting between antibonding and bonding $\mathrm{Cu} 3 \mathrm{~d} \mathrm{O} 2 \mathrm{p}$ states is enhanced so that the antibonding states are almost located above the Fermi level [unoccupied DOS of $\mathrm{Cu}_{2} \mathrm{O}$ ]. ${ }^{50}$

We arrive at the following concluding description of a model for the novel copper suboxide (near-)surface phase under investigation (see Fig. 10). First, we note that this copper suboxide phase exhibits chemical interactions of very similar bonding nature as near-surface or bulk compounds of copper(I) oxide. TPRS and TDS studies indicate that a catalytically selective acting copper is formed at the surface and sub-surface region after the exposure of oxidized copper with methanol at low pressures $\left(\sim 10^{-2}\right.$ to $\sim 10^{-6}$ mbar $)$ and at high reaction temperatures $(\sim 600 \mathrm{~K})$. The ex situ investigations indicate that if the methanol treatment is rapidly stopped a novel copper suboxide phase of $\mathrm{Cu}_{(x \geqslant 2.5)} \mathrm{O}$ is formed at the surface and near-surface region by diffusion of the surface oxygen species to the sub- and near-surface region and, additionally, by back-diffusion of the near-surface and bulk-dissolved oxygen species to the surface and sub-surface region. After quenching the reaction, the formation of a thermodynamically stable suboxide phase is favoured due to an intensification of the orbital interaction between oxygen and copper atoms as a consequence of the decreased metal-tometal coordination number. Thus, the catalytically selective

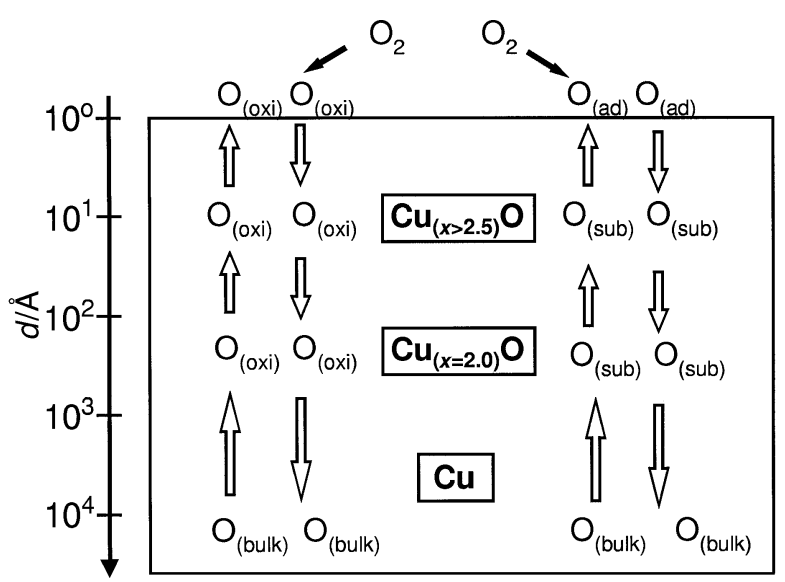

Fig. 10 Schematic diagram showing the different oxygen species found at the surface, near-surface and bulk region. 
acting copper surface phase exhibits only oxide-like oxygento-copper bonding interaction when it is investigated ex situ in vacuum.

This phase is assumed to be active in the total oxidation of methanol due to the very similar oxygen-to-copper bonding between $\mathrm{O} 2 \mathrm{p}$ and $\mathrm{Cu} 3 \mathrm{~d} / \mathrm{Cu} 4 \mathrm{sp}$ states if compared with the copper(I) oxide phase. The (near-)surface copper suboxide phase of $\mathrm{Cu}_{(x \geqslant 2.5)} \mathrm{O}$ catalyzes the total oxidation of methanol to carbon dioxide and water, i.e. the reduction of the oxide phase to metallic copper appeared, and thus, is not the active surface phase of the partial methanol oxidation reaction to formaldehyde and water or hydrogen. This difference in the catalytically active surface between in situ and ex situ analysis has severe consequences for consideration of the operation of copper as selective oxidation catalyst. Thus, for copper the catalytic state of oxygen is thermodynamically metastable towards the transition into an oxide state and a consequence is that the catalytically selective copper-oxygen phase is inaccessible in conventional ex situ UHV studies. The presented results call for an in situ study of the catalytic active copper phase.

\section{References}

1 I. Wachs and R. J. Madix, J. Catal., 1978, 53, 208

2 I. Wachs and R. J. Madix, Surf. Sci., 1979, 84, 375.

3 S. M. Francis, F. M. Leibsle, S. Haq, N. Xiang and M. Bowker, Surf. Sci., 1994, 315, 284

4 A. F. Carley, A. W. Owens, M. K. Rajumon and M. W. Roberts, Catal. Lett., 1996, 37, 79.

5 J. N. Russell, Jr., S. M. Gates and J. T. Yates, Jr., Surf. Sci., 1985, 163, 516.

6 M. A. Newton, J. Catal., 1999, 182, 357.

7 B. A. Sexton, A. E. Hughes and N. R. Avery, Appl. Surf. Sci., 1985, 22/23, 40 .

8 I. Wachs and R. J. Madix, Surf. Sci., 1978, 76, 531.

9 M. A. Barteau and R. J. Madix, in The Chemical Physics of Solid Surfaces and Heterogeneous Catalysis, ed. D. A. King and D. P. Woodruff, Elsevier, Amsterdam, 1982, vol. 4, ch. 4.

10 M. Bowker and R. J. Madix, Surf. Sci., 1980, 95, 195.

11 M. Bowker and R. J. Madix, Surf. Sci., 1981, 102, 542.

12 G. Ertl, Surf. Sci., 1967, 6, 208.

13 J. H. Onuferko and D. P. Woodruff, Surf. Sci., 1980, 95, 555.

14 M. Bader, A. Puschmann, C. Ocal and J. Haase, Phys. Rev. Lett., 1986, 26, 3273

15 J. G. Tobin, L. E. Klebanoff, D. H. Rosenblatt, R. F. Davis, E. Umbach, A. G. Bacon, D. A. Shirley, Y. Huang, W. M. Kang and S. Y. Tong, Phys. Rev. B, 1982, 26, 7076 .

16 J. Fink, N. Nücker, E. Pellegrin, H. Romberg, M. Alexander and M. Knüpfer, J. Electron. Spectrosc. Relat. Phenom., 1994, 66, 395.

17 N. Nücker, J. Fink, J. C. Fuggle, P. J. Durham and W. M. Temmerman, Phys. Rev. B, 1988, 37, 5138.

18 E. van de Riet, J. B. J. Smeets, J. M. Fluit and A. Niehaus, Surf. Sci., 1989, 214, 111.

19 H. Dürr, T. Fauster and R. Schneider, Surf. Sci., 1991, 244, 237.

20 S. R. Parkin, H. C. Zeng, M. Y. Zou and K. A. R. Mitchell, Phys. Rev. B, 1990, 41, 5432.

21 R. Feidenhans'l, F. Grea, R. L. Johnson, S. G. J. Mochrie, J. Bohr and M. Nielson, Phys. Rev. B, 1990, 41, 5420.

22 U. Döbler, K. Baberschke, D. D. Vevendsky and J. B. Pendry, Surf. Sci., 1986, 178, 679 .

23 M. Bader, A. Puschmann, C. Ocal and J. Haase, Phys. Rev. Lett., 1986, 57, 3273

24 A. W. Robinson, J. S. Somers, D. E. Ricken, A. M. Bradshaw, A. L. D. Kilcoyne and D. P. Woodruff, Surf. Sci., 1990, 227, 237.

25 F. Besenbacher and I. Stensgaard, in Chemical Physics of Solid Surfaces and Heterogeneous Catalysis, ed. D. A. King and D. P. Woodruff, "Phase Transitions and Adsorbate Restructuring at Metal Surfaces", Elsevier, Amsterdam, 1994, vol. 7, ch. 14.

26 (a) Th. Schedel-Niedrig, X. Bao, M. Muhler and R. Schlögl, Ber. Bunsen-Ges. Phys. Chem., 1997, 101, 994; (b) Th. Schedel-Niedrig, Fresenius' J. Anal. Chem., 1998, 361, 680.

27 J. J. Yeh and I. Lindau, Atomic Data and Nuclear Tables, Academic Press, New York, 1985, vol. 32, 1

28 X. Bao, B. Pettinger, G. Ertl and R. Schlögl, Ber. Bunsen-Ges. Phys. Chem., 1993, 97, 322.
29 X. Bao, G. Lehmpfuhl, G. Weinberg, R. Schlögl and G. Ertl, $J$. Chem. Soc., Faraday Trans., 1992, 88, 865.

30 X. Bao, M. Muhler, B. Pettinger, R. Schlögl and G. Ertl, Catal. Lett., 1993, 22, 215.

31 X. Bao, J. V. Barth, G. Lehmpfuhl, R. Schuster, Y. Uchida, R. Schlögl and G. Ertl, Surf. Sci., 1993, 284, 14.

32 A. R. McCabe, G. D. W. Smith and A. S. Pratt, Platinum Met. Rev., 1986, 30, 54.

33 W. E. Garner and F. S. Stone, Nature, 1946, 158, 909

34 H. Schmalzried, Chemical Kinetics of Solids, VCH, Weinheim, 1995, ch. 6 and 7.

35 (a) C. Wagner, Z. Phys. Chem. B, 1933, 21, 25; (b) C. Wagner, $Z$. Phys. Chem. B, 1933, 22, 181; (c) C. Wagner, Z. Phys. Chem. B 1933, 22, 212; (d) C. Wagner, Z. Electrochem., 1933, 39, 543.

36 C. Wagner, in Atom Movements, ASM, Cleveland, 1951, 153.

37 N. W. Hurst, S. J. Gentry, A. Jones and B. D. McNicol, Catal. Rev. Sci. Eng., 1982, 24, 233.

38 H. H. Kung, Transition Metal Oxides: Surface Chemistry and Catalysis, Elsevier, Amsterdam, 1989.

39 K. W. Jacobsen and J. K. Nørskov, Phys. Rev. Lett., 1990, 65, 1788.

40 F. Besenbacher, F. Jensen, E. Lægsgaard, K. Mortensen and I. Stensgaard, J. Vac. Sci. Technol. B, 1991, 9, 874.

41 J. Stöhr, NEXAFS Spectroscopy, Springer-Verlag, Berlin, 1992.

42 D. Briggs and M. P. Seah, Practical Surface Analysis by Auger and $X$-Ray Photoelectron Spectroscopy, John Wiley, New York, 1983.

43 The depth probed by the secondary-electron yield signal of $\sim 360$ $\AA\left(=3 \lambda_{\text {SEY }}\right)$ is about four times higher referred to the depth probed by the partial-electron yield signal of $\sim 90 \AA\left(=3 \lambda_{\mathrm{PEY}}\right)$. Additionally, the portion of the emitted electron intensity analyzed after the absorption along $0.25 \lambda_{\mathrm{SEY}} \approx 30 \AA(0.25 \approx$ $\left.\lambda_{\mathrm{PEY}} / \lambda_{\mathrm{SEY}}\right)$ is about $20 \%$ of the total emitted electron intensity detected in the SEY mode. This indicates that the spectral contribution of the surface and near-surface region (as probed with the PEY mode) in the SEY spectra can be estimated to about $20 \%$.

44 D. W. Fisher, J. Phys. Chem. Solids, 1971, 32, 2455.

45 L. A. Grunes, R. D. Leapman, C. N. Wilker, R. Hoffmann and A B. Kunz, Phys. Rev. B, 1982, 25, 7157

46 F. M. F. de Groot, M. Grioni, J. C. Fuggle, J. Ghijsen, G. A. Sawatzky and H. Petersen, Phys. Rev. B, 1989, 40, 5715.

47 J. Ghijsen, L. H. Tjeng, J. van Elp, H. Eskes, J. Westerink, G.A. Sawatzky and M. T. Czyzyk, Phys. Rev. B, 1988, 38, 11322.

48 M. Grioni, J. B. Goedkoop, R. Schoorl, F. M. F. de Groot, J. C. Fuggle, F. Schäfers, E. E. Koch, G. Rossi, J.-M. Esteva and R. C. Karnatak, Phys. Rev. B, 1989, 39, 1541.

49 M. Grioni, M. T. Czyzyk, F. M. F. de Groot, J. C. Fuggle and B E. Watts, Phys. Rev. B, 1989, 39, 4886.

50 M. Grioni, J. F. van Acker, M. T. Czyzyk and J. C. Fuggle, Phys Rev. B, 1992, 45, 3309

51 S. Nakai, T. Mitsuishi, H. Sugawara, H. Maezawa, T. Matsukawa, S. Mitani, K. Yamasaki and T. Fujikawa, Phys. Rev. B, 1987, 36, 9241

52 Gmelins Handbuch der anorganischen Chemie, Kupfer, Verlag Chemie, Weinheim, Teil B, 1958, p. 24

53 M. O'Keeffe and J.-O. Bovin, Am. Mineral., 1978, 63, 180.

54 The $\mathrm{O} 1 \mathrm{~s}$ and $\mathrm{Cu} 2 \mathrm{p}$ core-level spectra of the $\mathrm{Cu}_{(x=3.0)} \mathrm{O}$ (c) suboxide are shown in Fig. 5I and II together with the reference oxides $\mathrm{CuO}$ and $\mathrm{Cu}_{2} \mathrm{O}$, (a) and (b), and the copper metal (d). The corresponding $\mathrm{Cu}$ LVV Auger spectra are given in Fig. 5III. The $\mathrm{O} 1 \mathrm{~s}$ and $\mathrm{Cu} 2 \mathrm{p}$ spectra of the $\mathrm{Cu}_{(x=3.0)} \mathrm{O}$ phase are almost identically with that of the copper(I) oxide phase while the corresponding Auger spectrum (Fig. 5IIIc) exhibits the characteristic features of both the copper(I) oxide (peaks at 917 and $937 \mathrm{eV}$ ) and the copper metal (peaks at 919 and $939 \mathrm{eV}$ ) which suggests the co-existence of these two phases.

55 The intensity of the features have been estimated by fitting the peaks of the O K-edge XANES spectra of Figs. 6a-e with Gaussian broadened Lorentzians. The absorption edge was represented by an arctan function with the inflection point at the energy position at the maximum of the white lines. Feature 3 at $539.6 \mathrm{eV}$ of Fig. $6 \mathrm{e}$ is reduced in intensity by $77 \%$ (referred to feature $3^{\prime}$ of $\mathrm{Cu}_{2} \mathrm{O}$ (Fig.5a)) while the white line 1 at $533.8 \mathrm{eV}$ in the spectrum of Fig. 6e is increased by $8 \%$ in intensity (referred to white line $1{ }^{\prime}$ of $\mathrm{Cu}_{2} \mathrm{O}$ ). The strongest intensity increment of white line 1 of $17 \%$ (referred to $\mathrm{Cu}_{2} \mathrm{O}$ ) is observed in the spectrum of Fig. $6 \mathrm{~d}$ after a total methanol dose of $1.5 \times 10^{5} \mathrm{~L}$. In good agreement with the $\mathrm{Cu} \mathrm{L}_{2,3}$-XANES spectrum of copper(I) oxide the corresponding $\mathrm{Cu} \mathrm{L}{ }_{2}$-XANES spectra (not shown) reveal also a strong white line at $934.5 \mathrm{eV}\left(\mathrm{L}_{3}\right.$-edge $)$ and $954.5 \mathrm{eV}\left(\mathrm{L}_{2}\right.$-edge $)$ which are assigned to $\mathrm{Cu} 2 \mathrm{p} \rightarrow \mathrm{Cu} 3 \mathrm{~d}$ transitions. ${ }^{49,50}$ The intensities of the white lines in the $\mathrm{Cu} \mathrm{L}_{2,3}$-XANES spectra are 
increased by about $20 \%$ referred to the white line of $\mathrm{Cu}_{2} \mathrm{O}$ which strongly suggests that the unoccupied density of $\mathrm{Cu} 3 \mathrm{~d}$ states is increased in the novel copper suboxide (near-)surface phase.

56 The intensity of the features have also been estimated by fitting the peaks of the oxygen K-edge XANES PEY spectra of Figs. $7 \mathrm{a}-\mathrm{e}$ with Gaussian broadened Lorentzians on account of a closer inspection of the changes in the spectral overall shape with the total methanol dose. The absorption edge was represented by an arctan function with the inflection point at the energy position of the maximum of the white line. The corresponding $\mathrm{Cu} \mathrm{L}_{2,3}$ XANES spectra detected in the SEY mode (not shown) are in good agreement with the $\mathrm{Cu} \mathrm{L}_{2,3}$-XANES spectrum of copper(I) oxide (also detected with the SEY mode) while the intensity of the white line in the spectra increases during the methanol treatement by about $10 \%$ referred to the white line of $\mathrm{Cu}_{2} \mathrm{O}$. However, the increase of the white line intensity at the $\mathrm{Cu} \mathrm{L}_{2,3}$ edges in the near-surface/bulk- related spectra is about half the increase of the white line intensity of the (near-)surface related spectra.
57 Th. Neisius, PhD Thesis, Technische Universität Berlin, Berlin, 1997.

58 H. Werner, D. Herein, G. Schulz, U. Wild and R. Schlögl, Catal. Lett., 1997, 49, 109; R. Gottschall, J. Wölk, G. Mestl and R. Schlögl, in preparation.

59 P. Marksteiner, P. Blaka and K. Schwarz, Z. Phys. B, 1986, 64, 119.

60 L. E. Orgel, J. Chem. Soc., 1958, 4186.

61 S. Nagel, J. Phys. Chem. Solids, 1985, 46, 743.

62 M. Lenglet, K. Kartouni, J. Machefert, J. M. Claude, P. Steinmetz, E. Beauprez, J. Heinrich and N. Celati, Mater. Res. Bull., $1995,30,393$ 